\title{
Role Iron in Diabetes mellitus type 2 of the patients in province Diwaniya
}

\author{
Hussein Mahdi kreem AL-Mohammad, Murtadha Mohammed jawad ,Hayder abd ali ,Falah hussan
}

\section{ABSTRACT}

Background: Diabetes mellitus is a common health problem of the world. Iron may be a part of the cause of the disease and its Complications

Objectives: This study was designed to determine the relationship between the levels of iron indices and diabetes mellitus type 2. Type 2

Type of the study: Cross -sectional study.

Methods: diabetes mellitus is clinical condition characterized by hyperglycemia due to the absolute or relative deficiency of insulin. It is also followed by pathological abnormalities like impaired insulin secretion, peripheral insulin resistance, and excessive hepatic glucose production. Although type 2 diabetes mellitus is a multiple etiological disease, emerging scientific evidences show there is somewhat related to the disease with iron metabolism
Results: The study includes thirteen (15 female and 15 male) patient with Diabetes mellitus and (15 male and 15 female ) as the control. In the present study, significantly increased $(p<0.05)$ At ferretin, iron, transferitin, transferin saturated and significant decrease $(p<0.05)$ EIBS, TIBC

Conclusions: These results suggest that the role negative of increase iron in development Diabetes mellitus by a number of mechanisms.

Keywords: Diabetes mellitus, ferretin, transferring

Al-Kindy College Medical Journal 2017: Vol. 13 No.1 Page: 63-65

University of technical Alfurat Alawast, Institute technical of Diwaniya, Department Community Health

Received 15 $5^{\text {th }}$ Feb 2017, accepted in final $30^{\text {th }}$ March 2017 Corresponding to: Hussein Mahdi kreem AL-Mohammad
$\mathrm{D}$ iabetes mellitus (DM) is a group of metabolic diseases characterized by hyperglycemia resulting from defects in insulin secretion, insulin action, or both. The chronic hyperglycemia of diabetes is associated with long-term damage, dysfunction and failure of various organs, especially the eyes, kidneys, nerves, heart and blood vessels, that impose a tremendous burden on individual with diabetes and on the health care system (1). It is classified on the bases of pathogenic process that leads to hyperglycemia. The two broad categories of (DM) are designated type one (DM) and type two (DM). Other forms of (DM) are also categorized separately from these two types, and examples include gestational diabetes, congenital diabetes due to genetic defects of insulin secretion, cystic fibrosis-related diabetes, steroid diabetes induced by high doses of glucocorticoids, and several forms monogenic diabetes ${ }^{[2]}$. The metabolic syndrome is closely linked to insulin resistance and studies too tried to associate with iron overload. Increased serum ferritin, reflecting body iron overload, is often associated with measures of insulin resistance, such as elevated blood glucose and insulin levels. ${ }^{[3]}$. Anemia is a frequent condition in patients with Type 2 diabetes ${ }^{[4]}$. Iron metabolism in diabetes has been drawing interest. It is known that increased iron load is present inType 2 diabetes. ${ }^{[4]}$ Iron metabolism is regulated by hepcidin, a 25-amino-acid synthesized in the liver. Under normal circumstances, hepcidin controls the efflux of iron from duodenal enterocytes and macrophages ${ }^{[}{ }^{]}$ Under chronic inflammatory conditions Such as those observed in T2D, excessive cytokines such as IL-6 have a core function in Hepcidin production. IL- 6 acts directly on hepatocytes to stimulate hepcidin production ${ }^{[} 6^{]}$.
In recent years development of diabetes has been predicted with increased iron stores which is protected with iron depletion (7). Although the plasma concentration of iron is low total body The iron content is approximately 4 games in which a significant amount of iron is stored as ferritin and hemosiderin (8).

Methods : Thirty patients with Diabetes mellitus type 2 (15 female and 15 male ) and thirty normal (15 male and 15 female ) as control (normal) attendants in Al-Diwaniya Teaching hospital of period between January 2015 to December 2016 aged 18 to 74 years (median, 48.5 years) . The examination by specialist and their routine laboratory investigations Blood was drawn from both patients and controls. Serum levels of iron were estimated using the frozen calorimetric method ${ }^{[9],}$ total Iron Binding Capacity (TIBC) was estimated colorimetrically by the following procedure ${ }^{[10]:}$ An excess of iron is added to the serum iron to saturate the transferrin. The unbound iron is precipitated with basic magnesium carbonate. After centrifugation, the iron in the supernatant was determined.Unsaturated iron-binding capacity (UIBC), the amount of protein (apotransferrin) still available to bind iron, can be estimated from the formula: UIBC=TIBC - Serum iron. The ferritin quantitative kit based on a solid phase enzyme-linke immunosorbent assay (ELISA) was supplied by Monobind $\circledast$ Inc. USA. The assay system utilizes one rabbit anti-ferritin antibody for solid phase (microtitre wells) immobilization and a mouse monoclonal anti-ferritin antibody in the antibody enzyme horseradish peroxidase (HRP) conjugate solution. Estimated Total Iron Body Stores (ETIBS) were calculated using the following formula ${ }^{[11]}$ : ETIBS (in $\mu$ mol) $=$ (serum ferritin in $\mu g / L)$ * 143. Transferrrin saturation percentage 
(TS\%) was calculated from the following equation [11]: TS\% $=$ (Serum Iron/TIBC) ${ }^{*} 100 \%$ Transferrin concentration can be calculated using the following formula [12] Transferrin Conc. $(g / L)=S$.Iron ( $\mu$ mol/L)/ (TS\%*3.98) The formula is based on the maximal binding of $2 \mathrm{~mol} \mathrm{Fe} 3+/ \mathrm{mol}$ of transferrin and a molecular weight of $79,570 \mathrm{gm} / \mathrm{mol}$ for transferrin ${ }^{[1} 13^{]}$. A statistical analysis was made using SPSS, version 10.0. ${ }^{[14]}$.

Results : In our study, we found significant increased ( $p<$ 0.05 ) level of serum iron and Transferrin saturation (\%) while significant decrease $(p<0.05) \quad$ level of TIBC in diabetic patients. The result was shown in table significant decrease $(p<0.05)$ in Hemoglobin $(\mathrm{Hb})$, packed cell volume (PCV), Unsaturated iron-binding capacity (UIBC), Estimated Total Iron Body Stores (ETIBS), Transferrrin saturation percentage (TS\%), Transferrin concentration while The result was shown in table significant increase $(p<0.05)$ in a concentration of Ferritin.

\section{The table-1- showed Iron indices in patients with diabetes mellitus type 2 and control}

\begin{tabular}{|c|c|c|}
\hline Iron indices & $\begin{array}{c}\text { Patients Group } \\
\text { with Type 2 } \\
\text { diabetes }\end{array}$ & Control Group \\
\hline $\begin{array}{c}\text { S.Ferritin } \\
\text { (pmol/L) }\end{array}$ & $168 \pm 3.4^{*}$ & $164.34 \pm 115.49$ \\
\hline $\begin{array}{c}\mathrm{EIBS} \\
\text { (mmol/L) }\end{array}$ & $9.2 \pm 2.4^{*}$ & $10.46 \pm 7.35$ \\
\hline $\begin{array}{c}\mathrm{S} . \mathrm{Iron} \\
\text { (umol/L) }\end{array}$ & $17.85 \pm 6.52$ & $15.8 \pm 4^{*}$ \\
\hline TIBC (umol/l) & $51 \pm 4.3^{*}$ & $56.19 \pm 10.76$ \\
\hline TS\% & $32.91 \pm 11.11$ & $30 \pm 4.5^{*}$ \\
\hline $\begin{array}{c}\text { Transferrin } \\
\text { Conc. }(\mathrm{g} / \mathrm{L})\end{array}$ & $0.13 \pm 0.55^{*}$ & $0.15 \pm 0.03$ \\
\hline $\begin{array}{c}\text { UIBC } \\
\text { (umol/l) }\end{array}$ & $37 \pm 5.1^{*}$ & $38.56 \pm 11.34$ \\
\hline
\end{tabular}

Discussion : In recent years development of diabetes has been predicted with increased iron stores which is protective with iron depletion, Although plasma concentration of iron is low total body iron content is approximately $4 \mathrm{gm}$ in which a significant amount of iron is stored as ferritin and hemosiderin 15 , this agree with study condition. In fact iron level in serum is manifestation of storage iron, ferritin and there is increasing evidence that glucose metabolism is influenced by high ferritin level 16 .In the body. It has been observed frequent blood donation improves insulin sensitivity 17 . However, with the discovery of novel genetic disorders of iron metabolism, it is obvious that iron overload, irrespective of the cause or the gene involved, results in an increased incidence of type 2 diabetes. The role of iron in the pathogenesis of diabetes is suggested by 1 ) an increased incidence of type 2 diabetes in diverse causes of iron overload and 2) reversal or improvement in diabetes (glycemic control) with a reduction in iron load achieved using either phlebotomy or iron chelation therapy a link has been established between increased dietary iron intake, particularly eating red meat and increased body iron stores, and the development of diabetes. A causative link with iron overload is suggested by of the improvement in insulin sensitivity and insulin secretion with frequent blood donation and decreased iron stores 18,19. Iron excess and oxidative stress mediate apoptosis of pancreatic islets with a resultant decrease in insulin secretory capacity (20) . The mechanisms for insulin resistance include the possibility of iron overload causing resistance directly or through hepatic dysfunction 21

Conclusion : The result of the study explained relationship between iron overload and development induces Diabetes mellitus type 2 . The mechanisms for insulin resistance include the possibility of iron overload causing resistance directly or through hepatic dysfunction. In a study condition of patients with unexplained hepatic iron overload, most were found to be insulin resistant, which suggests a common etiologic link between hepatic iron, hepatic dysfunction, and insulin resistance.

\section{Refrences:}

1. American Diabetes Association Diagnosis and Classification of Diabetes mellitus. Diabetes Care; 36:(supp1.1):S67-74, 2013.

2. Craig, M.E.; Hattersley, A.; and Donaghue, K.C. "Definition epidemiology and classification of diabetes in children and adolescents"; J. Pediatr Diabetes, 12:3-12, 2009.

3. Mutru, O.; Laakso, M.; Isomaki, H.; Koota, K.( 1989). Cardiovascular Mortality in patients with rheumatoid arthritis. Cardiology; 76: 71-77.

4. Thomas, M.C., Maclsaac, R.J., Tsalamandris, C. et al., Unrecognized anemia in patients with diabetes: a crosssectional survey. Diabetes Care, 26, 11641169, 2003.

5. Gregor MF and Hotamisligil GS. Inflammatory mechanisms in obesity. Annu Rev Immunol 2011; 29: $415-445$

6. IWellen KE and Hotamisligil GS. Inflammation, stress, and diabetes. J Clin Invest 2005; 115:1111 1119.

7. Manuel J, Real F, Lopez-Bermezo A, Ricart W. Cross talk between iron metabolism and diabetes. Diabetes 2002; 51: 2348-54.

8. Beard J, Dawson B, Pinero D. Iron metabolism a comprehensive review. Netrev 1996; 54: 295-317.

9. Coles, E. H. (1980). Veterinary Clinical Pathology. $3^{\text {ed }}$ Ed. W. B. Sanders. Co. Philadelphia. Pp: 190192.

10. Artiss, J.D.; Vinogradov, S. Zak, B.(1981). Spectrophotometric Study of Several Sensitive Reagents for Serum Iron, Clin. Biochem. (14, 311315.

11. International Committee for Standardization in Hematology.(1991). The measurement of total and unsaturated iron binding capacity in serum. Br. J. Haematol. 38 : 281-290, 291-294

12. Rayssiguier, Y.; Mbega, J.D.; Durlach, V.; Gueux, E., Durlach, J., Giry, J.(1991). Mg and blood 
pressure. I. Animal studies. VIth International Mg Symposium, Indore.

13. .Freeman V. and Arneson W. (2007) Hemoglobin Production, Disorders, and Testing. In. "Clinical Chemistry: A Laboratory Prospective" Daves Co. , USA: . p:185

14. Morgan, EH.( 1992). Transferrin. Haeberli A eds. Human protein data $\mathrm{VCH}$ Weinheim.

15. Sorlie, DE.(1995). medical biostatistics and epidemiology examination and board review .first ed. Norwalk, Connecticut, Appleton and Lange; 47, 88.

16. Beard J, Dawson B, Pinero D. Iron metabolism a comprehensive review. Netrev 1996; 54: 295-317.

17. Hua NW, Stoohs RA, Facchini FS. Low iron status an Enhanced insulin sensitivity in lacto-ovo vegetarians. Brit J Nutr 2001; 86: 515-9.
18. Merkel PA, Simonson DC, Amiel SA, Plewe G, Sherwin RS, Pearson HA, Tamborlane WV: Insulin resistance and hyperinsulinemia in patients with thalassemia major treated by hypertransfusion. $\mathrm{N}$ Engl J Med 1988;318:809-814,

19. Cario H, Holl RW, Debatin KM, Kohne E: Insulin sensitivity and beta-cell secretion in thalassaemia major with secondary haemochromatosis: assessment by oral glucose tolerance test. Eur J Pediatr162:139-146, 2003.

20. Cooksey RC, Jouihan HA, Ajioka RS, Hazel MW, Jones DL, Kushner JP, McClain DA: Oxidative stress, beta-cell apoptosis, and decreased insulin secretory capacity in mouse models of hemochromatosis.Endocrinology 145:53055312, 2 004

21. Dandona $P$, Hussain MA, Varghese $Z$, Politis D, Flynn DM, Hoffbrand AV: Insulin resistance and iron overload. Ann Clin Biochem 20:77-79, 1983 